\title{
Development of energy-efficient IBC with IGBT module for photovoltaic applications
}

Research Article

Prasanna Kumar $\mathrm{C}^{1}$, Anand Rao ${ }^{2}$

${ }^{\top}$ PES University, Department of Electrical and Electronics Engineering, Bangalore, India

${ }^{2}$ Otis Elevator Company, SM-IEEE, PES University, Department of Engineering, Bangalore, India, Phone +917022250727, ORCID iD0000-0003-1226-2481

Received March 04, 2020; Accepted July 09, 2020

Abstract: The proposed study is improvised value-engineered modifications for the basic interleaved boost converter (IBC) by including relevant modifications in circuits, which is expected for a better performance in switching with reduction in losses. The newly modified IBC circuit with insulated gate bipolar transistor (IGBT) along with converter has been experimented by simulations and the results are tabulated to modified IBC with metal oxide silicon field effect transistors. Further experimental analysis and validations of the proposed simulation with hardware developed adopting model SKM195GB066D consisting of IGBTs is presented. This study further enhances and summarises the optimum utilisation and the performance of IBC with the proposed IGBT modules that synchronises power diode. Enhancing the simulation outcomes, the hardware is proposed and developed to be tested for a load up to $1.5 \mathrm{~kW}$ with the evaluation of key parameters such as efficiency of the converter.

Keywords: interleaved boost converter • efficiency • stability • power converters • switching frequency

\section{Introduction}

Internationally, there are active research progresses towards green energy and it is very evident that every country is more focused on the technologies for building capabilities in renewable energy systems. With more urge on cleaner energy, there are lot of areas that need to be focused for performance analysis and efficient utilisation with system integrations; in this regard, the happenings in solar energy are on rapid track for faster changes and quick adaptations on storage systems which is considered to be one of the major challenges. In common the energy storage is done using batteries and boost convertors of DC-DC are mediating to drive the required loads with few technical constraints in the converters that are very interesting to dive down further are, handling of high current at the input and a very high voltage at the output, introduction of undesired harmonics that will affect the performance of the system and high voltage gain needs to meet the load requirements with limited place for design. As the boost converters is one of the key components, it has been analysed and proved that soft switching has advantages with respect to the performance of the interleaved boost converter (IBC). IBC reduces the equivalent series resistance loss of output capacitor, and hence it reduces the volume of the capacitor ensuring that the design space is addressed. The era of metal oxide silicon field effect transistor (MOSFET) is fading and being replenished by IGBT in most of the advanced and latest applications. In the average current control analysed for high voltage gain with the use of coupled inductor and voltage multiplier circuit along with IBC with hardware of $170 \mathrm{~W}$ at switching of $100 \mathrm{kHz}$ has yielded efficiency of $95.1 \%$ as discussed by Diaz-Saldierna et al. (2012) and Freitas et al. (2015). Dynamic modelling and control of IBC with extremely high duty cycles capturing the reverse recovery, electromagnetic interference (EMI) effects and system behaviours with loads are elaborated with commutation process during zero voltage switching and zero current switching by Mahmoud et al. (2017) and Wen et al. (2006). Converter operated at $40 \mathrm{kHz}$ switching frequency had load driven of $1 \mathrm{~kW}$ resulted in the converter efficiency of 
94\% and IBC with active snubber operating zero voltage source for main switches and zero current source for auxiliary switches are applied and the magnetic components are designed with consideration of twice the switching frequency deliberated in Smith and Mc Cann (2014) and Ahmad et al. (2010). Handling of higher input currents and output voltages are experimentally analysed with developed hardware of $1 \mathrm{~kW}$ at a switching frequency of $60 \mathrm{kHz}$ by Pyosoo et al. (2011). Coupled inductors with current and voltage stress on switches, and reverse recovery problems of diodes by leakages are presented in continuous, discontinuous conduction modes and body control module as explained by Chien-Ming et al. (2014) and Ranoyca et al. (2014). An attempt is made to make series connection of two IBCs with operating duty cycle of 0.5 which has four times of voltage gain and the advantages of IBC compared with single stage boost are listed as decreased current stress, lower conduction losses ( $I^{2} R$ loss) and minimised current ripple due to phase difference of inductor currents. The cool metal oxide semiconductor (cool MOSFET) device has $1 \%$ more of converter efficiency compared with insulated gate bipolar transistor (IGBT) along with SiC diode converter suggested by Choi et al. (2011). The study by Ebrahim and Zahra (2017) discussed the two-phase critical mode power factor correction (CRM PFC) with interleaved technique. The study proposed a PFC regulator which gives a popular solution to suppress current harmonics in IBC. A $400 \mathrm{~W}$ conventional interleaved CRM PFC prototype converter is built and basic IBC switches are triggered with $180^{\circ}$ phase shift with signals generated using discrete analogue components based on Op-amp and SR flip-flop. As the trend is to go for pulse width modulated integrated circuits (PWM ICs), the discrete components are accordingly replaced. Huber et al. (2009) and Prasanna Kumar and Venugopal (2018) discussed parallel connection technique for PFC with CCM. The system developed for frequency of about $70 \mathrm{kHz}$ and it makes natural balance within the devices used. The circuit consists of MOSFET switches with PWM technique.

In the way to comprehend and understand the proposed work, the initial action taken for a comparison behavioural output for the existing system with a load of $3.73 \mathrm{~kW}$ as this is equivalent for domestic power applications of $5 \mathrm{hp}$ which is commonly used, during simulations the design values to drive the selected load of $5 \mathrm{hp}$ with the input fixed to $48 \mathrm{~V}$.

\section{Comparison of simulation results}

The comparison of simulation is proposed and carried out with the design values to drive a load of $5 \mathrm{hp}(3,730 \mathrm{~W})$ with its input supply fixed to $48 \mathrm{VDC}$ as this is expected to be driven from the renewable solar energy photovoltaic (PV) arrays stored in batteries. First, the traditional boost block simulation diagram is represented in Figure 1 with

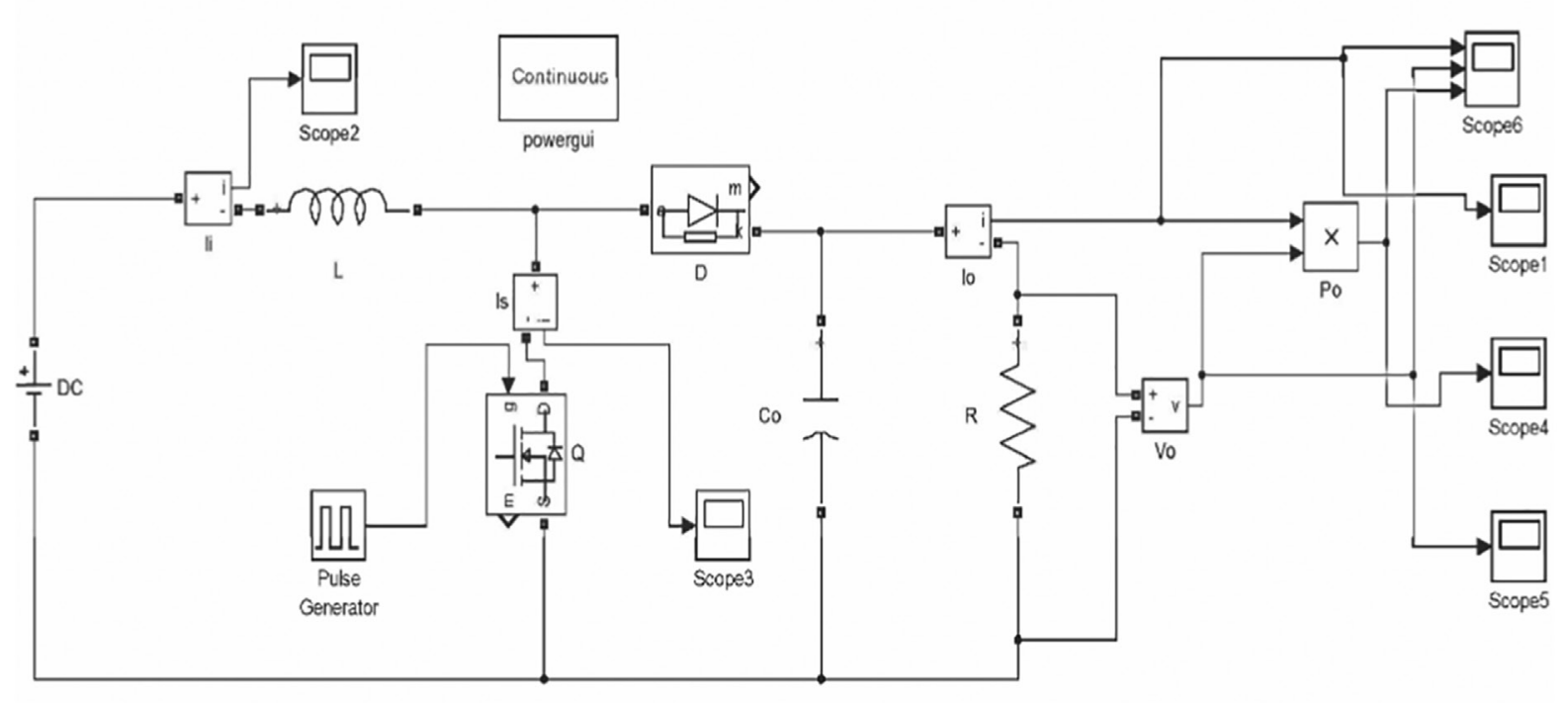

Fig. 1. Conventional boost simulation block diagram. 
MOSFETS and analysed in the simulation circuit of conventional boost and its simulation results obtained as output wave forms of power, current and voltages are shown in Figure 2. The simulated results of circuits obtained are $P_{0}=3,600 \mathrm{~W}, V_{0}=210 \mathrm{~V}$ and $I_{0}=15 \mathrm{~A}$ with an input of $48 \mathrm{~V} \mathrm{DC}$.

Further to strengthen the proposed concept, the power circuit is modified by replacing MOSFET and diode with IGBT as shown in Figure 3 wherein the IGBT acts as diode and its output parameters captured in similar lines of power, current and voltage are shown in Figure 4. Simulated results of circuits obtained are $P_{0}=3,700 \mathrm{~W}$, $V_{o}=230 \mathrm{~V}$ and $I_{o}=16.4 \mathrm{~A}$ with an input of $48 \mathrm{~V} \mathrm{DC}$.

The result obtained conveys that conventional boost is not advisable for high load applications as it requires high value of duty cycle. The IGBT switch has to be ON for long time and its output wave forms are represented in Figure 2. The system is such that it causes diode reverse recovery problem when conventional boost is operated
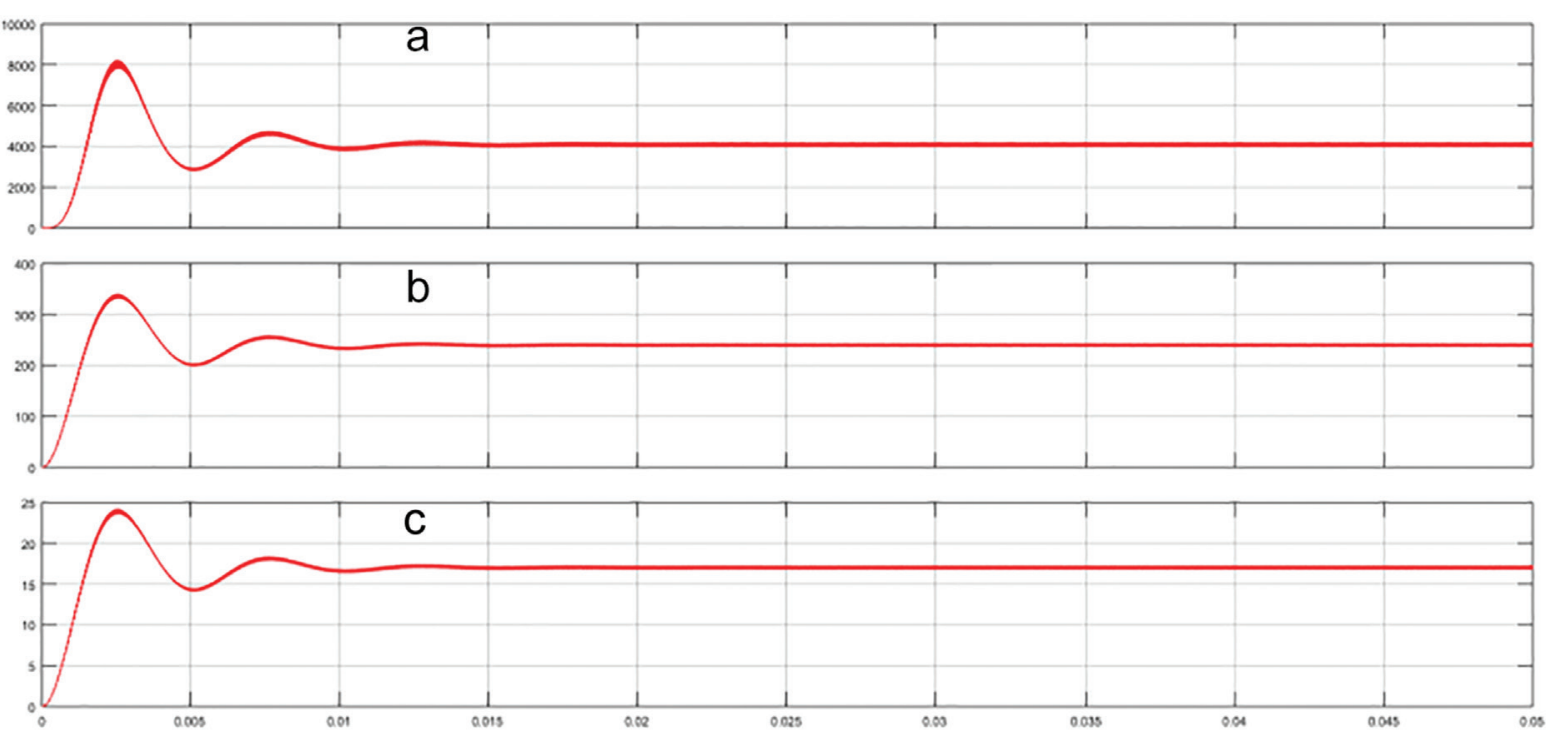

Fig. 2. Conventional boost simulation output wave forms: (a) power, (b) voltage and (c) current.

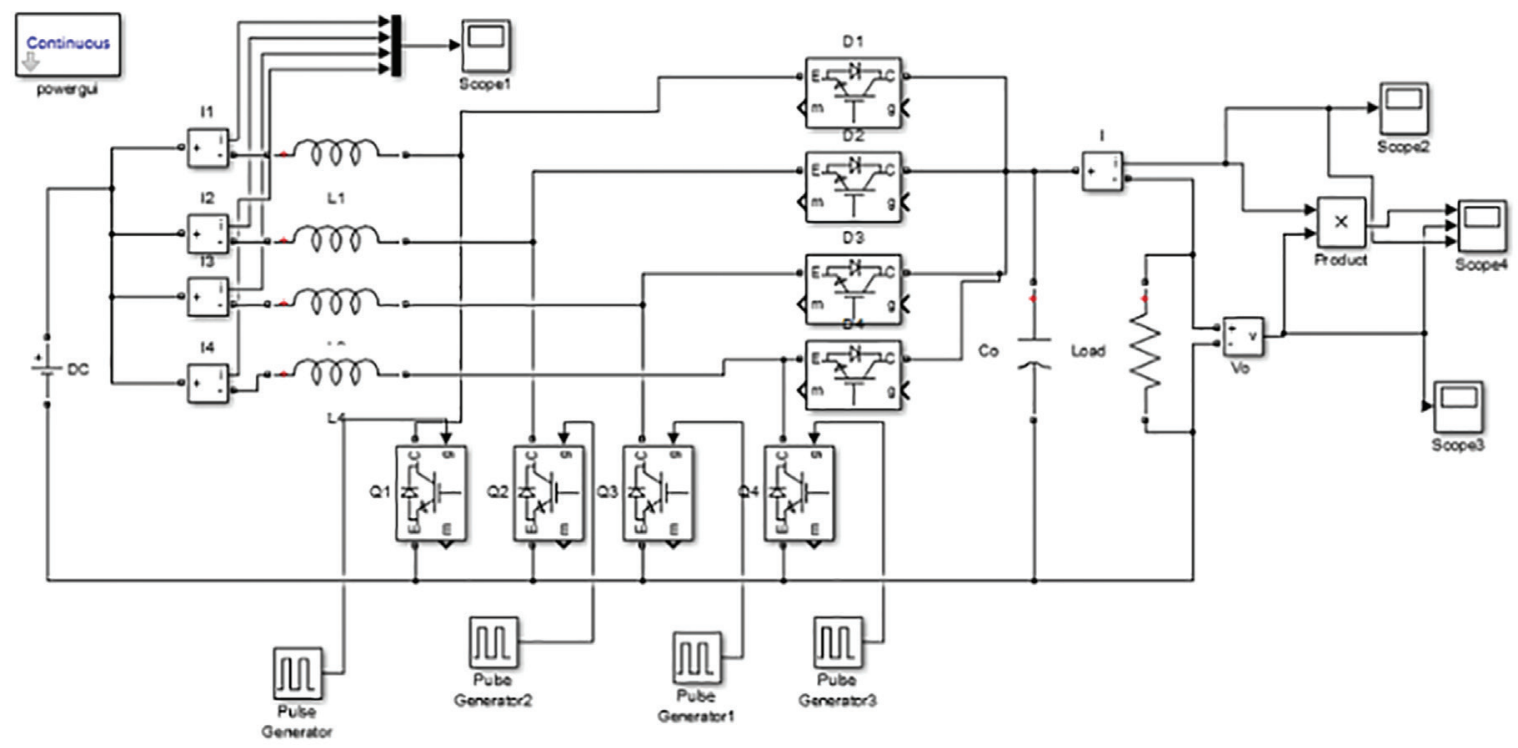

Fig. 3. Interleaved boost converter with insulated gate bipolar transistor as switch and diode simulation block diagram. 
at extremely high duty cycle. In that scenario, diode must sustain a short pulse current with high amplitude. These converters has poor dynamic response to load and line variations. Since parallel connections of converter has advantages, power density and thermal distribution are improved, and the overall cost reduced due to reduction in size and values of passive components and more scalability with various power requirements. The modification of classical IBC is in such a way that main switches and auxiliary switching devices and diodes are replaced with IGBTs. Table 1 shows the overview of comparison of simulation outcomes of different types of converters.

\section{Design and development of proposed work with IGBT module}

The design towards the development and realisation of the concept for the defined load of $3.73 \mathrm{~kW}$ was initiated with the assumption that the leakage inductances are neglected and utilisation of large output capacitor adapted to maintain constant output voltage and switches is taken under ideal operating conditions. The PV that is considered is capable enough to charge four $150 \mathrm{Ah}$ batteries to the operational level which are connected in series. The desired output being $230 \mathrm{~V}$ which is very common for domestic application with an input of $48 \mathrm{~V} \mathrm{DC}$ needs to be boosted with modified IBC. Since this converter is desired to operate with medium frequency with IGBTs, its industry application for manufacturing is optimum. As IGBTs are selected, the switching power-voltage-current frequency increases those results with higher switching losses that have indirect effects on the performance of converter. Hence, the frequency is fixed at $20 \mathrm{kHz}$ for this design which is considered for a load of $3.73 \mathrm{~kW}$.
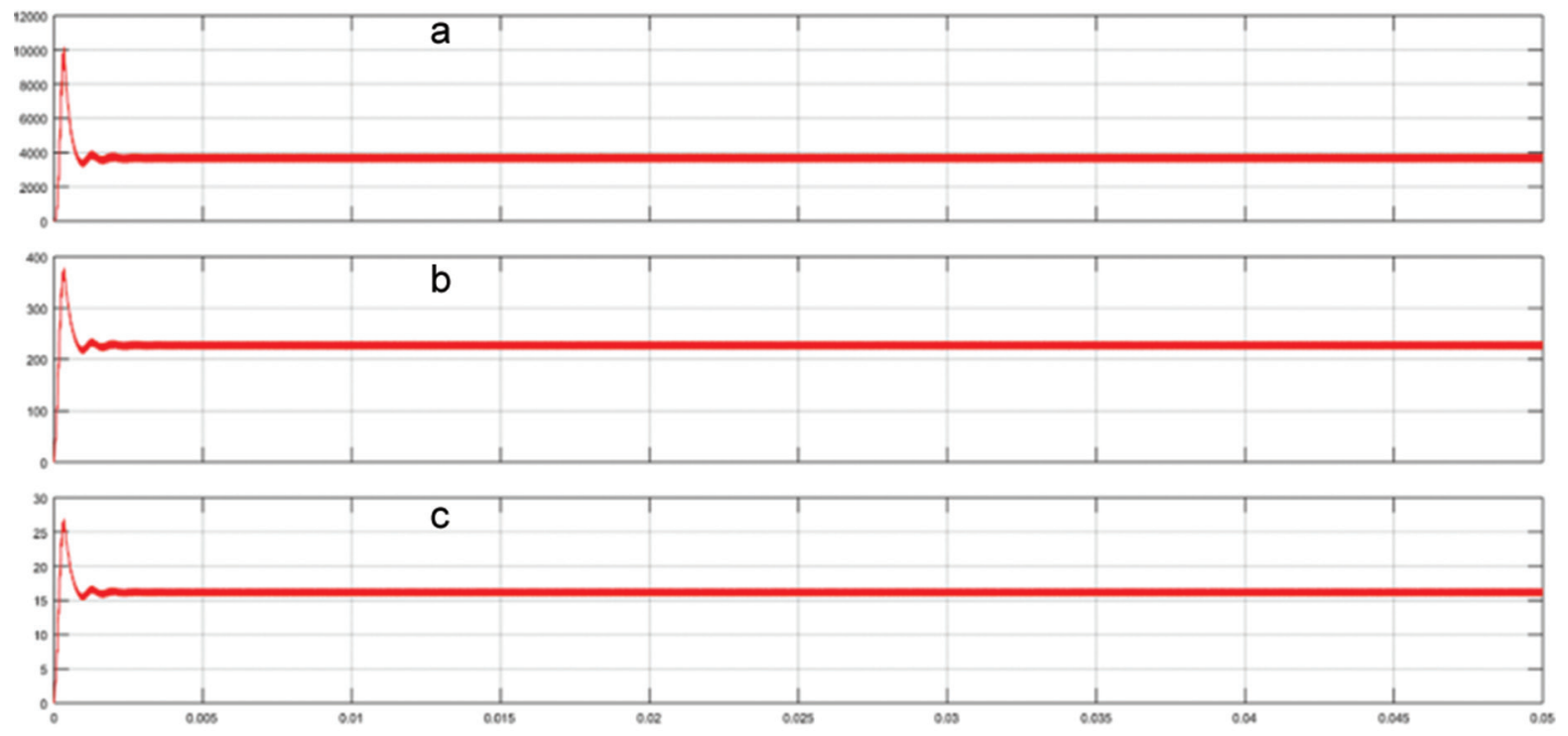

Fig. 4. Interleaved boost converter with insulated gate bipolar transistor as switch and diode simulation output wave forms: (a) power, (b) voltage and (c) current.

Table 1. Comparison of simulation outcomes

\begin{tabular}{lccc}
\hline Converter & Po (watts) & Vo (volts) & lo (amps) \\
\hline \hline Classical boost & 3,160 & 210 & 15 \\
Classical boost with IGBT & 4,085 & 240 & 17 \\
IBC & 3,380 & 225 & 15 \\
Three-stage IBC & 3,450 & 220 & 15.7 \\
Three-stage IBC with IGBTs & 3,740 & 230 & 16.25 \\
Four-stage IBC & 3,495 & 221 & 15.8 \\
Four-stage IBC with IGBTs & 3,605 & 225 & 16 \\
\hline
\end{tabular}

IGBT, insulated gate bipolar transistor; IBC, interleaved boost converter. 
With the above considerations defined, the block diagram of the proposed modified IBC configured for the design is shown in Figure 5, and the total system is driven with series-connected batteries for the desired voltage level of $48 \mathrm{~V}$.

Since PWM ICs and driver ICs operate on $12 \mathrm{~V}$, the regulated power source input is connected. As discussed in the earlier technical section, the IGBT module selected and finalised towards taking for hardware building is SKM195GB066D which has series connection of two IGBTs. The required modifications are carried out such that to use one module as main switch as well as diode and it is represented in Figure 5. Towards the implementation and realisation of hardware with two IGBT modules, the IGBT module has voltage rating of $600 \mathrm{~V}$ and current rating of $265 \mathrm{~A}$ at room temperature, even at higher temperature rise by $200 \%$ from the room temperature its current rating is about $200 \mathrm{~A}$. On state resistance, it is about $3 \Omega$ which is very good enough to take care in case of over voltage caused by stray inductance. The VCE saturation with positive temperature coefficient and high short circuit capability is about six times collector current. With the utilisation of the following equations and the requirements predefined for output voltage as $230 \mathrm{~V}$ with the load of $3.73 \mathrm{~kW}$, the components are decided for design and development and are represented in Table 2 with inductance ripple current and voltage which are limited to $10 \%$ and $5 \%$ of total input current and output voltage, respectively, by operating the switching 'frequency of $20 \mathrm{kHz}$ '.

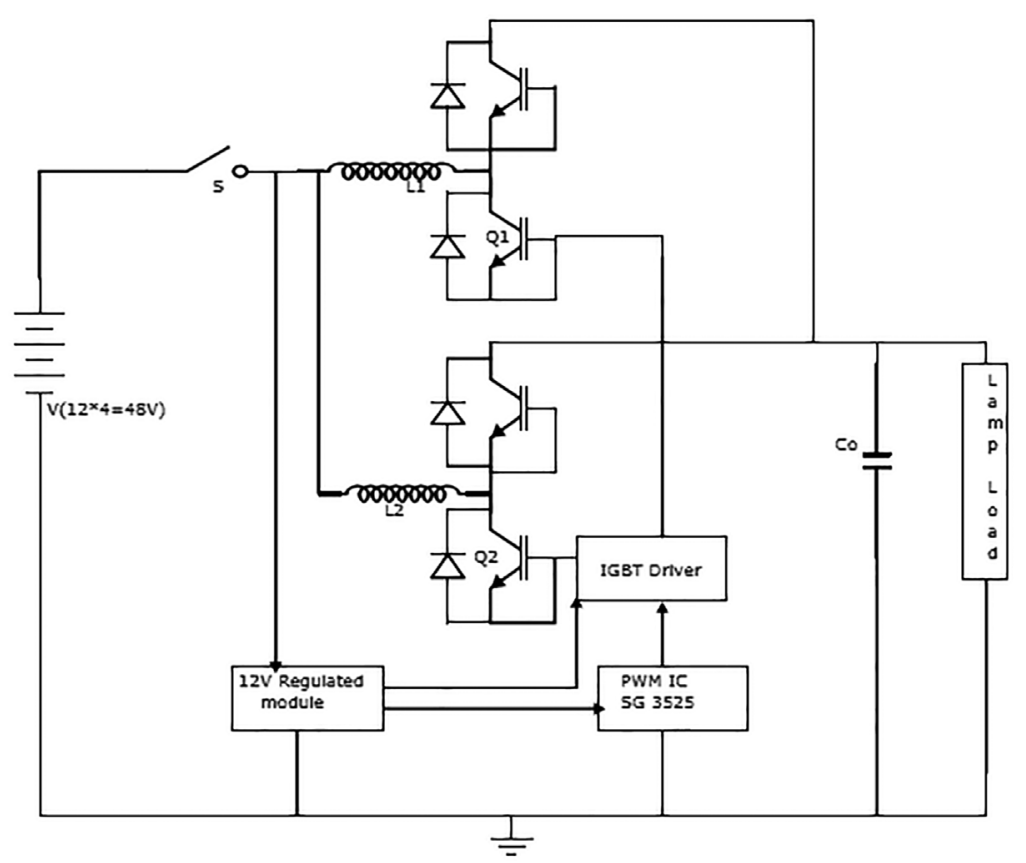

Fig. 5. Single line block diagram of proposed work.

Table 2. List of components

\begin{tabular}{ll}
\hline Component & Rating/name \\
\hline \hline Four batteries & 12 V, 150 Ah (luminous) \\
PWM ICs and IGBT driver & SG and TLP \\
Two IGBT modules & SKM195GB066D \\
Two snubbers and diodes & FKP6MHO920 and RHR30120 \\
Capacitor 4,700 MF, 450 V DC & Alcon Electronic \\
Current metre & CS7107GP \\
Shunt resistors (10 nos.) & $220 E$ \\
Heat sink & K-type \\
\hline
\end{tabular}

PWM ICs, pulse width modulated integrated circuits; IGBT, insulated gate bipolar transistor. 


$$
\begin{aligned}
& \frac{V_{o}}{V_{i}}=\frac{1}{(1-D)} \\
& L=\frac{D V_{i}}{\Delta I_{L} f_{s}} \\
& C=\frac{D V_{o}}{R \Delta V_{o} f_{s}} \\
& E=\frac{1}{2} L_{1} I_{1}^{2} \\
& A_{P}=\frac{2 E}{K_{w} K_{c} B_{m} J} \\
& n=\frac{L I_{m}}{A_{c} B_{m}}
\end{aligned}
$$

Towards better understanding of the magnetic circuit design, the total inductance $L$ derived from Eq. (2) is equally distributed for the modified IBC, hence $L_{1}=L_{2}$ resulting in input current is equally distributed, i.e. $I_{1}=I_{2}$. $E$ is the energy stored in the product area and core area. $K_{w}$ and $K_{c}$ are window and core constants of magnetic material considered to be 0.6 and 1 , respectively. $B_{m}$ is the maximum flux density and current density $J$ is 0.2 . Upon the input current and current density, the required area of the core and radius derived result in 100 total number of turns for the design with 8 SWG with a peak current $I_{m}$. The load selected is lamp for the desired level at the experimental test bench (Table 2), consisting of the components adopted for hardware proto sample testing based on earlier iterations.

As the component values are finalised, the simulation block diagram is represented in Figure 6 with PV module and its relevant output obtained with respect to power, voltage and current as shown in Figure 7, where it is near to the required values with $3.77 \mathrm{~kW}, 230 \mathrm{~V}$ and $16.4 \mathrm{~A}$ which indicates that this development can be very much suitable for PV applications in reality.

The realisation of hardware was prepared on the test bench for modified IBC along switch synchronisation with optimum utilisation of module suitable for PV application represented in Figure 8 as there are three metres incorporated for input and output voltages with the current drawn by the load. The hardware tested up to $31 \mathrm{~A}$ of source current can be seen in the test setup. Table 3 shows the hardware tested at various load values that are

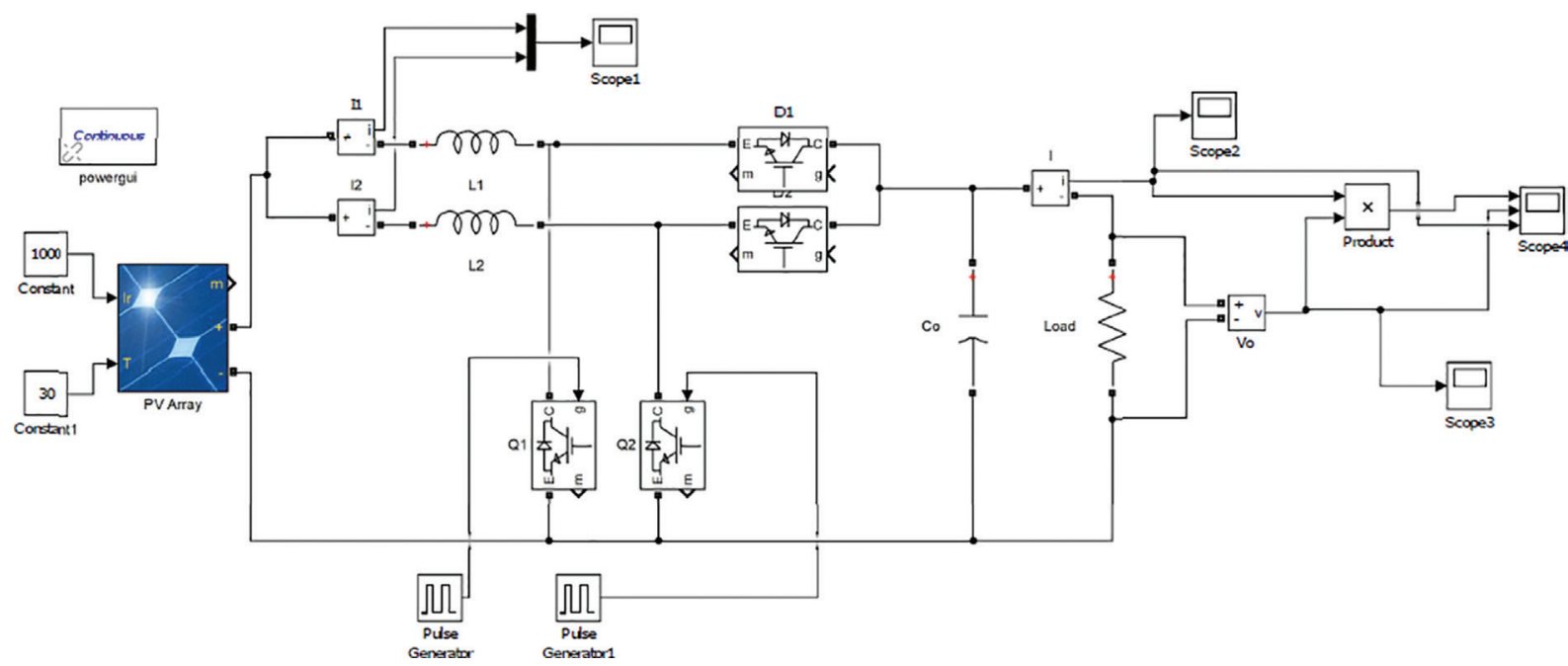

Fig. 6. Simulation block diagram of proposed work with photovoltaics. 

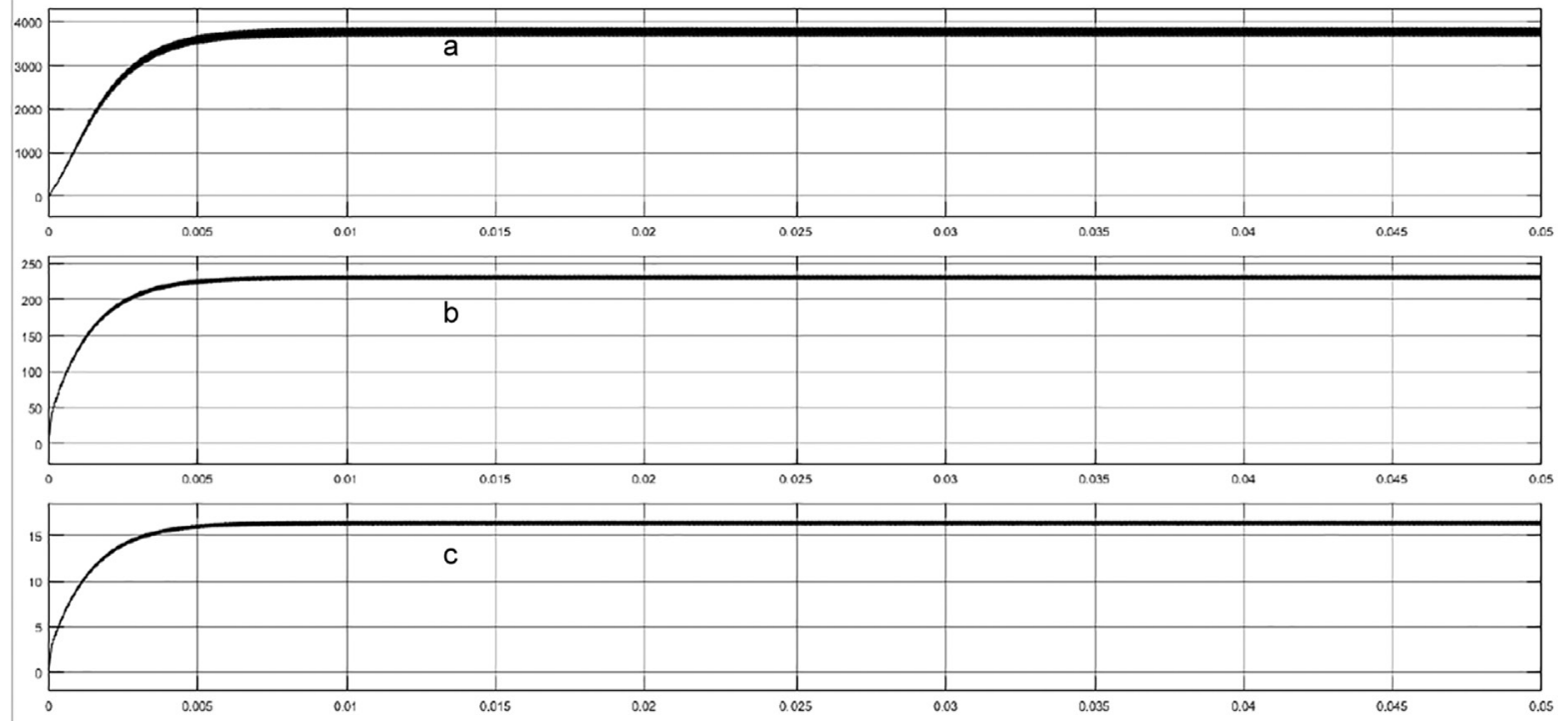

Fig. 7. Proposed concept interleaved boost converter simulation output wave forms: (a) power, (b) voltage and (c) current.

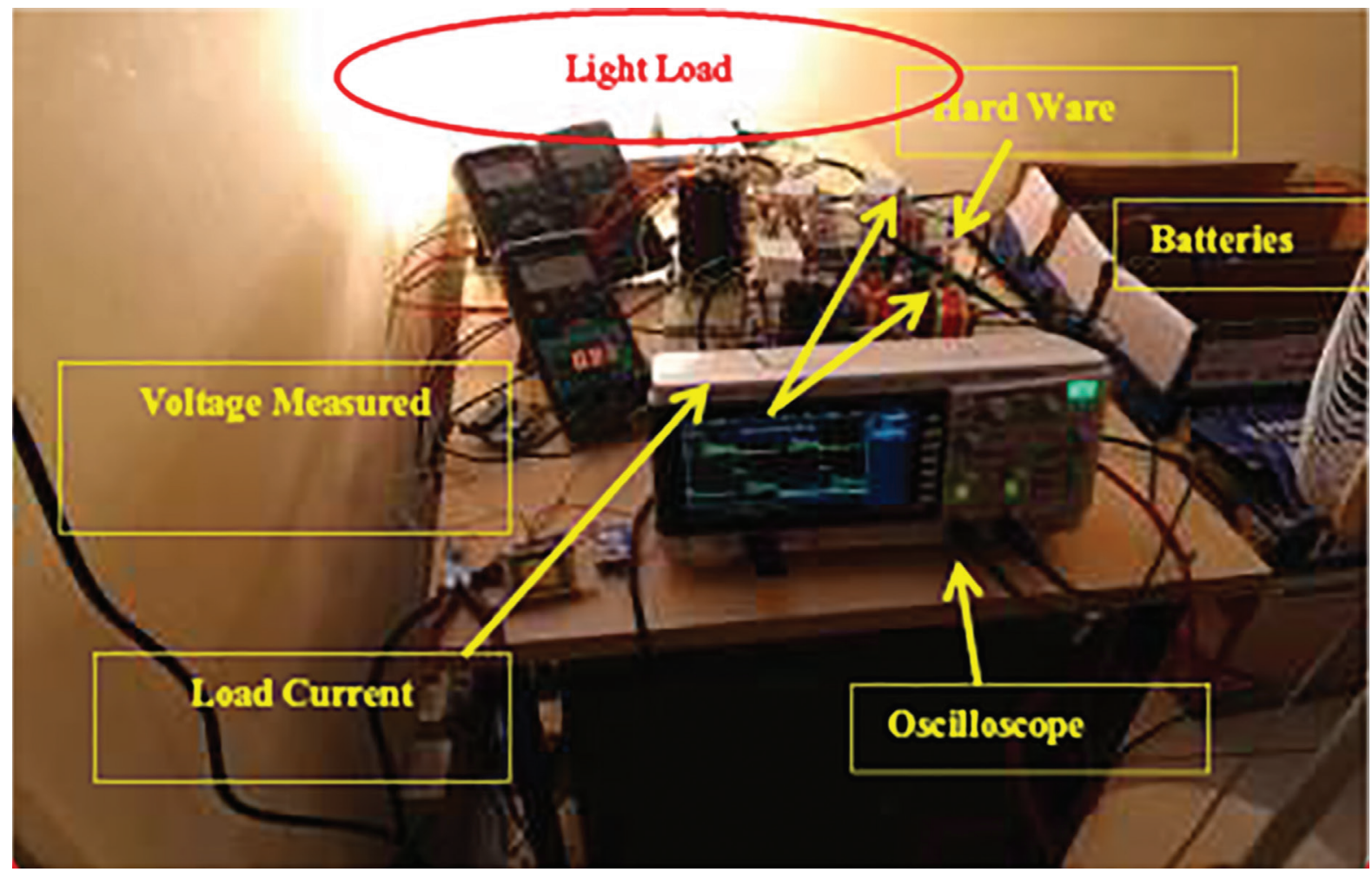

Fig. 8. Test bench hardware setup and validation

listed with neglecting the device losses at different loads. The readings captured with the test bench metres are tabulated based on which the values efficiencies are calculated and presented. From the behavioural outcome of the test bench hardware, it is observed that converter has better efficiency at higher loads with proper selection of output capacitor constant voltage maintained across the terminals. 
Table 3. Various loads hardware experimental results

\begin{tabular}{ccccccc}
\hline$l_{\text {in }}$ & $V_{\text {in }}$ & lo & $V_{0}$ & \multicolumn{1}{c}{$P_{\text {in }}$} & $P_{0}$ & \% \\
\hline \hline 3 & 50.1 & 0.43 & 222.5 & 150.3 & 95.675 & 63.65 \\
7 & 50.2 & 1.14 & 220.7 & 351.4 & 251.598 & 71.598 \\
10 & 49.6 & 1.89 & 220.1 & 496 & 415.99 & 83.86 \\
13 & 49.5 & 2.38 & 219.9 & 643.5 & 523.36 & 81.33 \\
14 & 49.2 & 2.6 & 219.7 & 688.8 & 571.22 & 82.93 \\
17 & 48.9 & 3.31 & 218.6 & 831.3 & 723.566 & 87.04 \\
20 & 48.6 & 3.78 & 218.7 & 972 & 826.68 & 85.04 \\
21 & 48.5 & 4.04 & 218.3 & $1,018.5$ & 881.932 & 86.6 \\
24 & 48.3 & 4.7 & 217.8 & $1,159.2$ & $1,024.13$ & 88.35 \\
26 & 48 & 5.08 & 217.3 & 1,248 & $1,103.88$ & 88.45 \\
27 & 47.9 & 5.27 & 217.4 & $1,293.3$ & $1,186.7$ & 88.58 \\
28 & 47.9 & 5.48 & 216.5 & $1,341.2$ & 1,194 & 85.41 \\
29 & 47.9 & 5.49 & 217.5 & $1,389.1$ & $1,291.3$ & 85.96 \\
31 & 47.6 & 5.97 & 216.3 & $1,475.6$ & $1,342.6$ & 87.51 \\
32 & 47.6 & 6.19 & 216.9 & $1,523.2$ & $1,414.9$ & 98.155 \\
33 & 47.4 & 6.76 & 209.3 & $1,564.2$ & & 90.455 \\
\hline
\end{tabular}

\section{Conclusion}

This study presented towards a step on modifications in the IBC which are incorporated in the conventional boost IBC by replacing MOSFETs and diodes with IGBTs. The simulation comparison of results in terms of output parameters such as current, voltage and power is very promising for the proposed model. The modifications in the IBC adopted with use of multiple switches have seen the reduction in the ripple and initial transients from the output wave forms as observed as IBC still holds on to the output parameter without changes. With the confidence on simulation outputs, the building of hardware was decided and developed with IGBT module as switch and diode. The hardware was tested and presented which demonstrated good efficiency when the load was above $1 \mathrm{~kW}$. The hardware was limited and tested up to $1.5 \mathrm{~kW}$ and resulted in efficiency of $91 \%$. This study also demonstrated the optimum and efficient system that eases the designer to select the components that are in line with current 'technology'.

\section{References}

Ahmad, S. S., Makbul, A. and Abdul, H. M. Y. (2010). Dynamic evolution control of interleaved boost dc-dc converter for fuel cell application. In: 2010 Conference Proceedings IPEC, Singapore, 2010, pp. 869-874.

Chien-Ming, W., Chang-Hua, L., Shih-Yung, H., ChienMin, L. and Jyun-Che, L. (2014) Analysis, design and performance of a zero-current-switching pulse-width modulation interleaved boost $\mathrm{dc} / \mathrm{dc}$ converter. IET Power Electronics, 7(9), pp. 24372445.

Choi, S., Agelidis, V. G., Yang, J., Coutellier, D. and Marabeas. (2011). Analysis design and experimental results of a floating-output interleaved-input boost-derived DC-DC high-gain transformer-less converter. IET Power Electronics, 4(1), 168-180.
Diaz-Saldierna, L. H., Leyva-Ramos, J., Ortiz-Lopez, M. G. and Reyes-Malanche, J.A. (2012). Current-controlled switching regulator using a DC-DC converter with high-step-down voltage gain. IET Transactions on Power Electronics, 5(7), pp. 1147-1153.

Ebrahim, B. and Zahra, S. (2017). High voltage gain dc-dc converters based on coupled inductors. IET Power Electronics, 11(3), 434-452.

Freitas, A. A. A., Tofoli, F. L., Júnior, E. M. S., Daher, S. and Antunes, F. L. M. (2015). High-voltage gain dc-dc boost converter with coupled inductors for photovoltaic systems. IET Transactions on Power Electronics, 8(10), 1885-1892.

Huber, L., Irving, B. T. and Jovanovic, M. M. (2009). Closed-loop control methods for interleaved $\mathrm{DCM} / \mathrm{CCM}$ boundary boost PFC converters. In: Proceedings of the 24th Annual IEEE Applied 
Power Electronics Conference and Exposition, Washington, USA, 15-19 February.

Mahmoud, F., Navid, M., Ehsan, A. and Hosein, F. (2017). High voltage gain interleaved dc-dc converter with minimum current ripple. IET Power Electronics, 10(14), pp. 1924-1931.

Prasanna Kumar, C. and Venugopal, N. (2018). Performance and stability analysis of series cascaded, high-gain, interleaved boost converter for photovoltaic applications. Power Electronics and Drives, 3(1), 85-97.

Pyosoo, K., Sanghyuk, L., Junsung, P. and Sewan, C. (2011) High step-up interleaved boost converters using voltage multiplier cells. In: Power Electronics and ECCE Asia (ICPE \& ECCE), 2011 IEEE 8th International Conference on, IEEE, pp. 2844-2851.
Ranoyca, N., Alencar, L. S., Fernando, L. T., Paulo, P. P., Demercil de Souza, O., Jr. and Barreto, L. H. S. C. (2014). Soft switching high-voltage gain dc-dc interleaved boost converter. IET Power Electronics, 8(1), 120-129.

Smith, N. and Mc Cann, R. (2014). Analysis and simulation of a multiple input interleaved boost converter for renewable energy applications. In: Proceedings of the 36th International Telecommunications Energy Conference (INTELEC), Vancouver, Canada, 28 September-2 October 2014.

Wen, J., Jin, T. and Smedley, K. (2006). A new interleaved isolated boost converter for high power applications. In: Proceedings of the 21st Annual IEEE Applied Power Electronics Conference and Exposition, Dallas, USA, 19-23 March 2006. 